This item was submitted to Loughborough's Research Repository by the author.

Items in Figshare are protected by copyright, with all rights reserved, unless otherwise indicated.

\title{
A reliability-based approach to mission planning in multi-platform phased missions
}

PLEASE CITE THE PUBLISHED VERSION

PUBLISHER

(C) Institute of Electrical and Electronics Engineers (IEEE)

VERSION

VoR (Version of Record)

LICENCE

CC BY-NC-ND 4.0

\section{REPOSITORY RECORD}

Prescott, Darren R., and J.D. Andrews. 2009. "A Reliability-based Approach to Mission Planning in Multiplatform Phased Missions”. figshare. https://hdl.handle.net/2134/5483. 
This item was submitted to Loughborough's Institutional Repository (https://dspace.lboro.ac.uk/) by the author and is made available under the following Creative Commons Licence conditions.

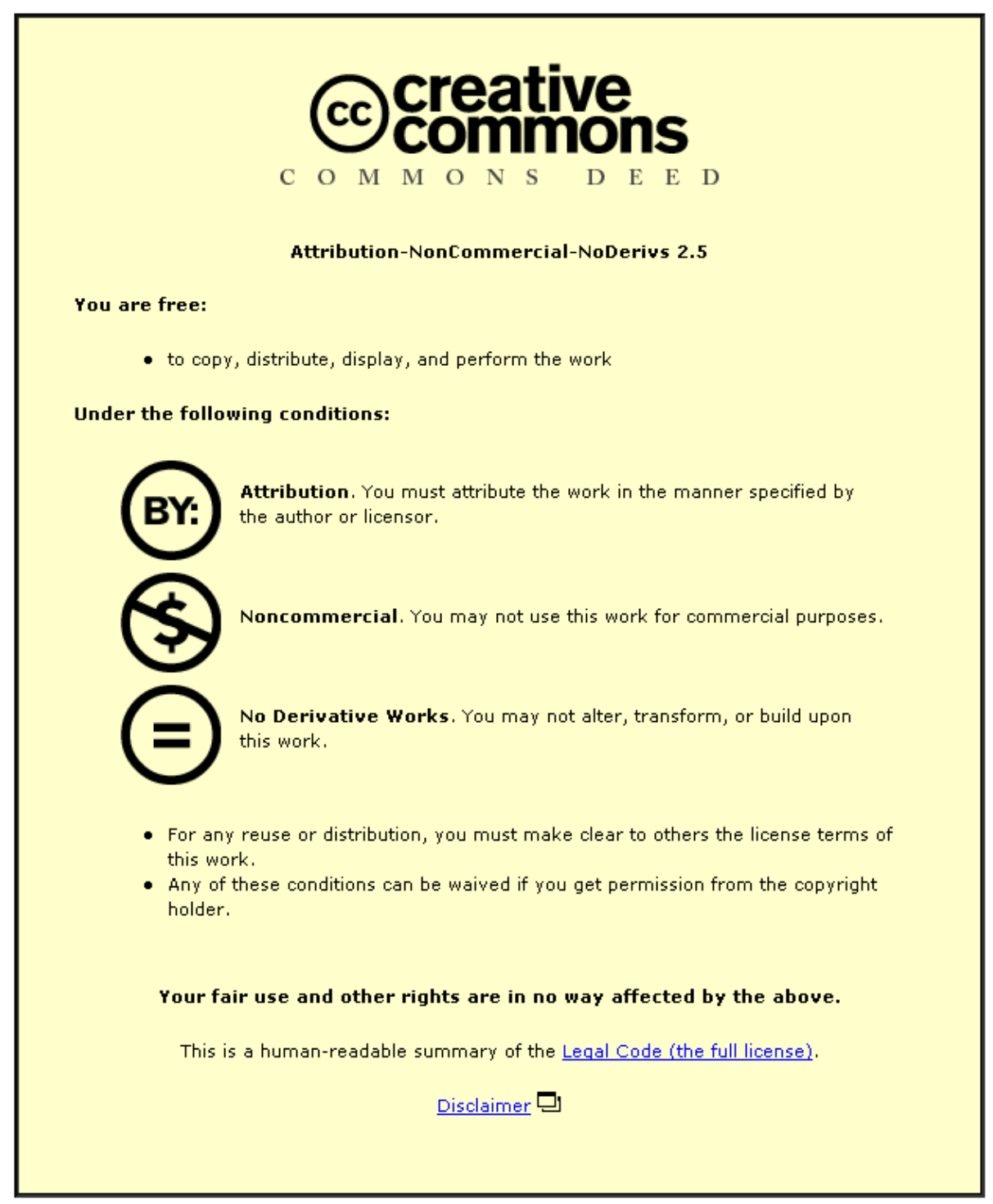

For the full text of this licence, please go to: http://creativecommons.org/licenses/by-nc-nd/2.5/ 


\section{A Reliability-Based Approach to Mission Planning in Multi-Platform Phased Missions}

\author{
Darren PRESCOTT \\ Department of Aeronautical and Automotive Engineering \\ Loughborough University \\ Loughborough, LE11 3TU, UK \\ E-mail: D.R.Prescott@lboro.ac.uk
}

\author{
John ANDREWS \\ Department of Aeronautical and Automotive Engineering \\ Loughborough University \\ Loughborough, LE113TU, UK \\ E-mail: J.D.Andrews@lboro.ac.uk
}

\begin{abstract}
Many systems perform phased missions consisting of several distinct, sequential phases. Mission success depends on the successful completion of all mission phases. Increasingly, for example in military theatre, platforms operating phased missions are required to collaborate in order to achieve an overall mission objective, with specific platform phases containing specific tasks that contribute to that objective. Particularly, but not exclusively, in the case of autonomous vehicles, the calculation of phase and mission failure probabilities can be used to assist in making decisions on the future course of a mission. This paper describes how this decision making process can be implemented.
\end{abstract}

Keywords- phased mission; mission planning; multi-platform system

\section{INTRODUCTION}

There is an increasing demand for systems not to work in isolation but instead to work in conjunction with other systems in order to achieve certain objectives. This is certainly the case in military theatre and is becoming increasingly important with the introduction of Network Enabled Capability (NEC) or Network Centric Warfare (NCW). These bring a requirement for a flexible, agile and cost-effective achievement of required military effect. The deployment of autonomous vehicles is also becoming increasingly common, due to the fact that they are capable of operating in areas or situations that would be of unacceptably high risk to equivalent manned vehicles. When they are, it is imperative that these platforms are capable of making decisions based not only on the objectives of the individual platforms, but also according to the objectives of the overall mission in which they are collaborating. It is assumed within this paper that the platforms under consideration are non-repairable and that the failures of individual components are independent.

\section{A. Single Platform Phased Missions}

It will most often be the case that, when a number of platforms work together in order to achieve a certain mission objective, that the platforms themselves will perform phased missions. A phased mission conducted by an individual platform is a mission that consists of several distinct, sequential phases. In order that the phased mission be successfully completed each of these individual phases must be successfully completed. An example of such a phased mission is an aircraft flight, which, as depicted in Figure 1, has seven distinct phases: taxi to runway, take off, climb to a cruising altitude, descent, land, taxi to terminal. The consequences of failure of such missions are often high and for this reason accurate analysis methods are required to calculate the probability of the missions failing. When calculating the probability in any particular phase the fact that the platform must have successfully completed all previous phases has to be taken into account

\section{B. Multi-Platform Phased Missions}

A multi-platform phased mission is performed by a number of individual platforms, each of which performs its own phased mission which will be similar in form to that shown in the example in Figure 1. As part of its own phased mission each platform performs a task, or a number of tasks (referred to here as mission tasks), that contribute to the achievement of a mission objective. The mission objective can only be achieved through the cooperation of the various platforms taking part in the mission. The mission tasks performed by the platforms are not necessarily sequential since it is possible that platforms may carry out in parallel tasks that contribute to the achievement of the mission objective. Figure 2 shows a representation of an example multi-platform phased mission to which two platforms, A and B, are contributing. Each platform has three phases of its own mission. However, it can be seen in the figure that the phases of the two platforms are not

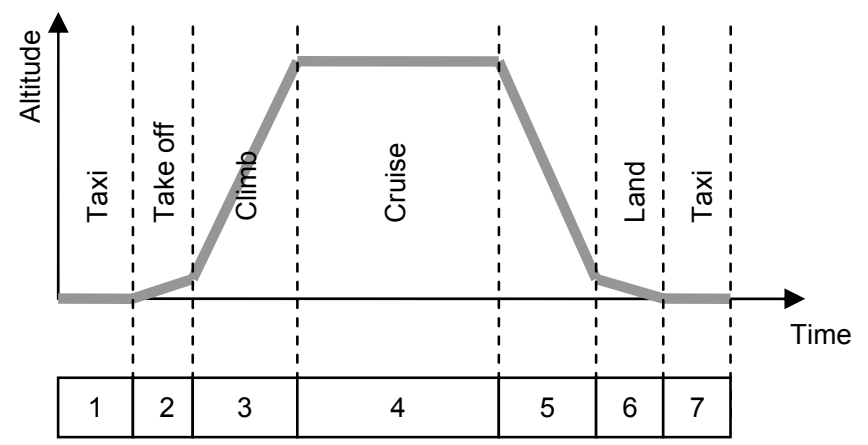

Figure 1. An aircraft flight and its 7 constituent phases.

concurrent, except in the case of the platforms' second phases, which are identical in length and start and end at the same time. A situation such as this could occur where the two platforms 


\begin{tabular}{|c|c|c|c|c|c|}
\hline \multirow[t]{2}{*}{ Platform A: } & \multicolumn{2}{|r|}{1} & 2 & \multicolumn{2}{|l|}{3} \\
\hline & & & & & \\
\hline \multirow[t]{2}{*}{ Platform B: } & & 1 & 2 & \multicolumn{2}{|c|}{3} \\
\hline & & & & \multicolumn{2}{|c|}{ i } \\
\hline Mission: & 1 & 2 & 3 & 4 & 5 \\
\hline
\end{tabular}

Figure 2. Representation of a multi-platform phased mission.

are required to collaborate closely during their second phases and their first and third phases are taken up by, for example, reaching and leaving the destination at which the collaboration must take place. Also apparent from Figure 2 is the fact that the overall mission consists of a number of distinct phases, during which mission failure would occur if there were failures of either or both of the platforms during that period. For example, failure in mission phase 2 would occur if platform A was to fail in mission phase 2 (in the part of its own first phase that relates to mission phase 2) or if platform B was to fail in its own first phase.

It is possible, when a multi-platform phased mission is considered, that not all platform phases will be relevant to the achievement of the desired mission objective. Clearly, it must be the case that all platform phases prior to any in which mission tasks are performed must be completed successfully and hence will be a part of the mission, since the platforms will not be able to perform later phases in their mission without first successfully completing earlier phases. For example, consider again the mission representation shown in Figure 2. Let platforms A and B be unmanned aerial vehicles (UAV) with their respective phases (1,2 and 3 ) representing cruise to mission location, cruise and perform mission task and cruise to new location to await further orders. Since the second platform phases (in mission phase 3 ) are the ones that contribute to the mission tasks, both platforms must complete their first phases in order to have any chance of success in their second phases, in mission phase 3 . Now consider the objectives of the mission. There are a number of possibilities, two of which are now so that the return of the two UAVs to the locations at which they await further orders is not considered to be vital. In this case the mission will take the form shown in Figure 3, with the final two mission phases not contributing to the achievement of the mission objective and hence the multi-platform phased mission only consists of three phases. However, if one were to consider the success of either of the platforms in their own mission, it is likely that the platform must perform all three of its own mission phases in order to successfully complete its mission.

\section{MISSION PLANNING}

In this section a decision making strategy that may be used to assist in mission planning for groups of autonomous platforms operating multi-platform phased missions is presented. However, whilst the strategy is presented in the context of autonomous vehicles and an associated autonomous mission planning process, it could equally be used to assist in decision making for other multi-platform phased missions, autonomous or otherwise. Three main tools that are required by the strategy are outlined and one of these, relating to mission prognostics, is discussed in Section III.

\section{A. Decision Making Strategy}

A decision making strategy for multi-platform phased missions has been proposed for use in a mission planning context [1]. It is based on three main tools, a Prognostics tool, a Diagnostics tool and a Reconfiguration tool. A representation

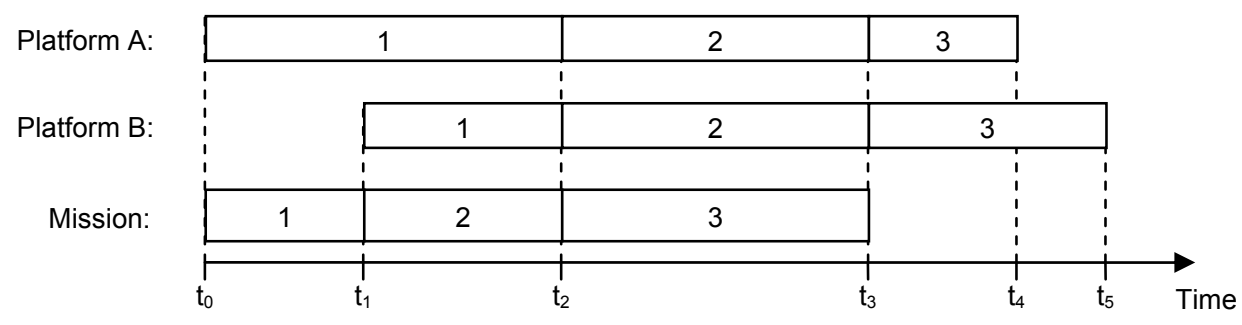

Figure 3. A multi-platform phased mission with updated mission objective.

discussed. Consider first that, in order for the mission to be considered a success, platform A and platform B must both successfully perform the mission task required of them, then they must both successfully move to the new location to await further orders. If this is the case then the overall mission will take the form of that given in Figure 2, having 5 separate mission phases. However, consider that the mission is considered to be of such importance that the mission tasks that must be completed can be completed at the cost of the UAVs of the strategy is shown in Figure 4. For a typical mission, an original mission configuration is produced. The prognostics tool produces a prediction of the likely success of the mission, which is used to make a decision as to whether or not the mission should begin. If the prognosis is acceptable the mission begins and the diagnostics tool reports faults or changing conditions to the prognosis tool as soon as they are diagnosed. This allows the prognostics tool to produce a new prediction of the likelihood of mission success and this is then tested for 


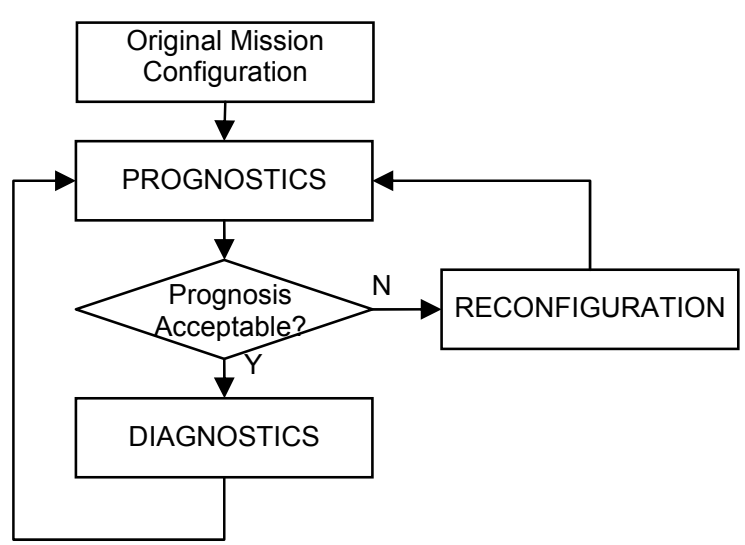

Figure 4. A decision making strategy for use in mission planning.

acceptability. If at any point the prognosis for the mission under consideration is unacceptable the reconfiguration tool produces a new mission configuration for which a prognosis is produced and verified for acceptability before either the mission continues or another reconfiguration takes place.

\section{MisSION PROGNOSTICS}

It has been proposed that the mission prognosis tool outlined in Section II-A should be based on phased mission reliability models of the multi-platform phased missions under consideration $[1,4]$. In this context, the decision about whether or not a particular mission configuration is acceptable will be informed by whether or not the failure probability for the mission lies within acceptable limits. The decision making strategy dictates that the mission failure probabilities are demanded in two separate circumstances, before a mission begins (initial failure probabilities) and once the mission is underway and diagnostics information is reported (updated failure probabilities). Initial failure probabilities help to decide whether the mission should begin. Updated failure probabilities take into account the latest mission information and help to decide whether the mission should continue.

It is possible to calculate failure probabilities for individual platform phases and the entire missions of these platforms [2] as well as for the phases of the multi-platform phased missions and the overall mission [3]. Methods have been presented which allow the calculation of updated failure probabilities for platforms and overall mission given various pieces of diagnostic information. It is possible to take account of component failures, both single and multiple failure modes [2], events external to the systems in question, such as weather or other emerging threats [2], system subsystem or functional failures for which precisely which components have failed is unknown [2] and also the exact time that the diagnosis is provided and a mission prognosis is required [3].

\section{A. Requirements}

When considering a prognostics capability as part of a decision making strategy that can be used in a mission planning process for autonomous systems, there are two main requirements. These are speed and accuracy. Speed of prognosis is required in order that quick decisions may be made as to the future course of the mission. This speed must come in two areas: model construction and model quantification. The speed of model construction is necessary to allow phased mission models representing the appropriate phase or mission failure conditions to be quickly constructed, given that decisions may be required quickly after changes in circumstance which are reported by a diagnostics capability or when a prognosis must be provided for a new mission configuration. The speed of model quantification is an obvious requirement in hoping to provide mission prognoses as quickly as possible. The requirement for accuracy comes from the need for the autonomous systems to be able to make well-informed decisions as to the future course of their mission. For this reason it would be advantageous to make few or no approximations when performing quantitative analysis of the phased mission reliability models.

\section{B. Suitable Methods of Analysis}

A number of methods have been utilised to analyse phased missions, such as Fault Tree Analysis (FTA) [5], Markov analysis [6], Binary Decision Diagrams (BDD) [7,8] and Cause Consequence Analysis (CCA) [9]. The suitability of each of these analysis methods for use in a prognostics capability is shown in Table 1. FTA is unsuitable for this application since a full quantitative analysis requires use of the inclusion-exclusion expansion, which is inefficient or even impossible in terms of computational time. Applying approximations is a possibility but the introduction of noncoherency to fault trees when the success of previous phases is taken into account when considering mission failure in a certain phase means that the accuracy of these approximations cannot be guaranteed. Markov models can have large state spaces, meaning quantification can take too long for this application, despite the fact that numerical methods could be used which could produce the required accuracy. BDDs offer the analytical technique that is most likely to meet the requirements of the mission planning process. Their structure brings with it a rapid quantification process, with no need for approximations to be used. CCA has been shown to have great potential for use in a mission planning process for autonomous systems in [4], where a method of analysis was presented which allowed the different platform configuration options that are possible in working to achieve a certain mission objective to be considered. The method also allows platform redundancy to be considered, where more than one platform is able to perform certain mission tasks. Since the method allows for the use of BDD analysis it also offers the potential to achieve the required speed of analysis.

TABLE I. METHODS OF ANALYSIS AND THEIR SUITABILITY FOR USE IN THE MiSSION PLANNING PROCESS.

\begin{tabular}{|l|c|c|}
\hline \multicolumn{1}{|c|}{ Method } & Speed & Accuracy \\
\hline Fault Tree Analysis & $\boldsymbol{x}$ & $\boldsymbol{x}$ \\
\hline Markov Analysis & $\mathbf{x}$ & $\checkmark$ \\
\hline Binary Decision Diagrams & $\checkmark$ & $\checkmark$ \\
\hline Cause Consequence Analysis & $\checkmark$ & $\checkmark$ \\
\hline
\end{tabular}




\section{CONCLUSIONS}

A mission planning approach for multi-platform phased missions has been presented. At its core is a decision making strategy, within which a reliability-based prognostics capability is required. The phased mission analysis techniques that could provide this prognostics capability were briefly discussed and BDD and CCA were identified as the two most likely to be capable of meeting the required characteristics of speed and accuracy of mission prognosis.

\section{REFERENCES}

[1] D.R. Prescott, R. Remenyte-Prescott, and J.D. Andrews, “A systems reliability approach to decision making in autonomous multi-platform systems operating a phased mission," Proceedings of the Annual Reliability and Maintainability Symposium, 2008, Las Vegas, USA (CD-ROM).

[2] D.R. Prescott, R. Remenyte-Prescott,. S. Reed, J.D. Andrews, and C.G. Downes, "A reliability analysis method using bdds in phased mission planning," Proc. IMechE, Part O: J. of Risk and Reliability, 2009, Vol.223, No.2, pp.133-143.
[3] D.R. Prescott, J.D. Andrews, and C.G. Downes, "Multi-platform phased mission reliability modelling for mission planning," Proc. IMechE, Part O: J. Risk and Reliability, 2009, Vol.223, No.1, pp.27-39.

[4] D.R. Prescott, and J.D. Andrews, "A cause consequence analysis approach to modelling multi-platform phased missions," Proceedings of the 18th AR2TS (Advances in Risk and Reliability Technology Symposium), Loughborough University, UK, 2009, pp.303-317.

[5] J.D. Esary, and H. Ziehms, "Reliability analysis of phased missions," Reliability and Fault Tree Analysis, 1975, pp.213-236.

[6] M. Smotherman, and K. Zemoudeh, "A non-homogeneous markov model for phased mission reliability analysis," Transactions on Reliability, 1989, Vol.38, pp.585-590.

[7] R. LaBand, and J.D. Andrews, "Phased mission modelling using fault tree analysis," Proceedings of the IMechE, Part E: Journal of Process Mechanical Engineering, 2004, Vol.218, No.E2, pp.83-91.

[8] X. Zang, H. Sun, and K.S. Trivedi, "A BDD-based algorithm for reliability analysis of phased-mission systems," IEEE Transactions on Reliability, 1999, Vol.48, pp.50-60.

[9] G. Vyzaite, S.J. Dunnett, and J.D. Andrews, "Cause consequence analysis of non-repairable phased missions," Reliability Engineering and System Safety, 2006, Vol.91, No.4, pp.398-406. 